\title{
AS ODR'S (ONLINE DISPUTE RESOLUTION) COMO SISTEMA MULTIPORTAS DE RESOLUÇÃO DE CONFLITOS
}

\section{ARTIGO ORIGINAL}

FREIRE, Déborah Vieira ${ }^{1}$, LIMA, Carla Jessica Rodrigues ${ }^{2}$, ROCHA FILHO, Edilson Martins da ${ }^{3}$

FREIRE, Déborah Vieira. LIMA, Carla Jessica Rodrigues. ROCHA FILHO, Edilson Martins da. As ODR'S (Online Dispute Resolution) Como Sistema Multiportas De Resolução De Conflitos. Revista Científica Multidisciplinar Núcleo do Conhecimento. Ano 06, Ed. 06, Vol. 16, pp. 63-74. Junho de 2021. ISSN: 2448-0959, Link de acesso: https://www.nucleodoconhecimento.com.br/lei/sistema-multiportas,

DOI: 10.32749/nucleodoconhecimento.com.br/lei/sistema-multiportas

\section{RESUMO}

O presente artigo tem como finalidade abordar o sistema multiportas de resolução de litígios, a luz das normas processuais previstas no Código de Processo Civil de promoção pelo judiciário da solução consensual dos conflitos, devendo todos os sujeitos processuais, neles inclusos magistrado, os membros do Ministério Público, Advogados e as próprias partes estimularem a conciliação, mediação, arbitragem e outros meios alternativos de solução consensual de litígios. Ademais, tivemos como objetivo analisar os meios alternativos de resolução de conflitos previstos em nossa legislação e as ODR's (online dispute resolution) e assim proceder com um comparativo entre os métodos convencionais de solução de conflitos. Pretendeu-se também identificar a utilização das ODR's (online dispute resolution) como método preventivo de eventuais ações judiciais e a adaptação da legislação brasileira a essa nova tendência. A presente pesquisa foi realizada através de revisão bibliográfica,

\footnotetext{
${ }^{1}$ Pós-graduada em Direito Processual Civil. Professora do Curso de Graduação da Faculdade de Ensino Superior da Amazônia Reunida - FESAR.

${ }^{2}$ Graduada em Direito.

${ }^{3}$ Graduando de Direito.
} 
utilizando-se de método dedutivo, com uma abordagem qualitativa acerca do estudo analítico das ODR's (online dispute resolition), em face dos métodos tradicionais de resolução de controversas, trazendo, as suas funcionalidades como um sistema multiportas de resolução de demandas. Ademais, analisou-se ainda como a tecnologia pode auxiliar o Estado na desjudicialização dos conflitos e ao jurisdicionado na própria solução do caso concreto de forma mais célere, efetiva e econômica. Desse modo, foi trazido o conceito das ODR's (online dispute resolution), o seu funcionamento, bem como os seus benefícios e como as primeiras plataformas virtuais foram surgindo e como são utilizadas atualmente no Brasil. Assim, as ODR's é a grande aposta dos entusiastas da tecnologia e do próprio Poder Judiciário para 0 seu descongestionamento, evitando ainda a litigância massiva existente no Brasil.

Palavras-chave: ODR (online dispute resolution), Sistema Multiportas, Solução Consensual de Conflitos.

\section{INTRODUÇÃO}

Estamos a bordo de uma revolução tecnológica que transformará fundamentalmente a forma como vivemos, trabalhamos e nos relacionamos. Esta frase é de autoria de Klaus Schwab (2016, p. 223), em seu livro "A Quarta Revolução Industrial".

O autor é fundador e diretor executivo do Fórum Econômico Mundial, e maior defensor da intitulada quarta revolução industrial ou indústria 4.0. Na seara jurídica também não é diferente, passamos por um processo de transição da advocacia artesanal ao direito 4.0.

O direito 4.0 traz, em síntese, o uso dessas novas tecnologias desenvolvidas pela quarta revolução tecnológica, como o uso da inteligência artificial, automação, big data, internet das coisas, para o ambiente jurídico.

Como exemplo, podemos destacar o uso da inteligência artificial sendo testada nos tribunais como modo de dar celeridade e efetividade na prestação jurisdicional. O STF utiliza-se de uma ferramenta denominada Victor, que faz a anamnese dos recursos repetitivos e suscetíveis de repercussão geral. Já no STJ o Sócrates é um sistema 
que faz a análise dos recursos e elabora minuta de decisões, de forma automatizada. Ao todo no Brasil, já são mais de 13 tribunais testando o uso de inteligência artificial nos processos judiciais.

Assim, tendo em vista que a revolução tecnológica traz também grandes inovações para o mundo jurídico, se faz necessário o estudo de métodos consensuais de conflitos servidos pela tecnologia, que se prestam para solucionar demandas que eventualmente seriam judicializadas, com maior eficiência e economia, é o que se demonstrará no presente trabalho.

\section{A RESOLUÇÃO ON LINE DE CONFLITOS COMO SISTEMA MULTIPORTAS DO PODER JUDICIÁRIO}

Antes de passar para a análise da propriamente dita dos meios alternativos de solução de litígios, sobretudo aqueles oferecidos através do uso de tecnologias, importante conhecer a concepção da justiça multiportas e sua adaptação na lei processual vigente, e para tanto, utilizará como referência o texto dos processualistas Fredie Didier Jr e Hermes Zaneti Jr. "Justiça Multiportas e Tutela Constitucional Adequada: Autocomposição em Direitos Coletivos” (2017), vejamos:

"[...] A justiça estatal clássica, adjudicada pelo juiz, não é mais o único meio adequado para a solução de conflitos. Ao lado desta justiça de porta única, surgem novas formas de acesso: a justiça se torna uma justiça multiportas. Nesta nova justiça, a solução judicial deixa de ter a primazia nos litígios que permitem a autocomposição e passa a ser última ratio, extrema ratio. Assim, do acesso à justiça dos tribunais passamos ao acesso aos direitos pela via adequada de composição, da mesma forma que, no campo do processo, migramos da tutela processual, como fim em si mesmo, para a tutela dos direitos, como finalidade do processo. A doutrina reafirma esta mudança, que significa, além da necessidade de adequação da justiça, a emergência da atipicidade dos meios de solução de conflitos: "o direito de acesso ao Direito, pilar fundamental do Estado de Direito, vem sofrendo profundas transformações. Deixou de ser um direito de acesso ao Direito através do direito de acesso aos tribunais para passar a ser um direito de acesso ao direito, de preferência sem contato ou sem passagem pelos tribunais [...] Agora, o direito de acesso aos tribunais é um direito de retaguarda, sendo seu exercício legítimo antecedido de uma série de filtros [...]. (DIDIER JR; ZANETI JR, 2017) 
O último relatório Justiça em Números (2020)[4], principal fonte das estatísticas oficiais do Poder Judiciário, elaborado pelo Conselho Nacional de Justiça (CNJ) anualmente concluiu que o Judiciário brasileiro finalizou o ano de 2019 com 77,1 milhões de processos em tramitação, que aguardavam alguma solução definitiva.

A litigiosidade massiva tem gerado o abarrotamento do Poder Judiciário, o que levou o legislador a editar normas com o objetivo de trazer solução para o gargalo de novas ações e das já existentes.

Os meios consensuais de solução de litígio são mais econômicos do que um processo judicial, muitas vezes mais efetivo tendo em vista que as próprias partes decidem o resultado do seu conflito, sem a imposição de um terceiro julgador.

As ODR's (online dispute resolition) são um ambiente virtual onde serão celebrados acordos extrajudiciais diários, utilizando-se de não apenas um meio de resolução de conflito, mas aquele que melhor atender à necessidade das partes naquele caso concreto.

Em 11 de março de 2020, a Organização Mundial da Saúde (OMS) caracterizou o surto da doença causada pelo novo coronavírus (COVID-19) como uma pandemia. A designação reconhece que, no momento, existem surtos de COVID-19 em vários países e regiões do mundo.

No Brasil, a pandemia em razão do COVID-19 foi declarada em 17 de março de 2020. A partir dessa declaração o Estado Brasileiro, com o apoio dos governos estaduais e municipais em ações conjuntas vem traçando metas e planos para contingenciar os efeitos e consequências da pandemia. Até então, as orientações técnicas da Organização Mundial da Saúde, bem como as demais instituições de referência, são de que o isolamento social é, até que se encontre tratamento eficaz para a doença, a forma mais segura de prevenção do contágio.

Desse modo, o mundo como um todo vem adotando estrategicamente, cada país à sua maneira, o distanciamento social como melhor forma de evitar a doença, o que 
tem apresentado resultados efetivos nos atuais estudos de principais instituições de referência, como a própria OMS.

Assim, algo que já era realidade em nossa vida, mas de forma ainda moderada e contida, passou com a pandemia, a ser imposta. Fomos de forma abrupta, compelidos a viver em um ambiente totalmente virtual. Isso porque, todas as atividades consideradas não essenciais passaram a ser realizadas de forma remota, em home office, o ensino presencial passou a ser prestado de forma remota, os Tribunais suspenderam os prazos processuais, ou seja, todas as atividades possíveis foram adaptadas para serem prestadas através do uso da internet e tecnologia.

$\mathrm{Na}$ verdade, a pandemia só veio para acelerar um processo tecnológico já existente. A tecnologia e as plataformas virtuais, das mais variadas formas, também tiveram que se "adaptar" ao isolamento social, isso porque a busca por esses serviços e produtos cresceu exponencialmente, que nem mesmo os mais entusiastas da tecnologia, acreditavam ser de forma tão rápida e intensa como foi imposta pelo combate ao COVID-19.

Neste contexto, vimos também os Tribunais se adaptarem para não cessar a prestação jurisdicional, e nesse sentido, a tecnologia tem sido fundamental. Todavia, importante ressaltar ainda, que a COVID-19 trouxe um aumento muito grande na judicialização das demandas, todas em razão do reflexo da doença nas diversas áreas da vida do jurisdicionado.

Desse modo, o sistema multiportas toma ainda mais importância como auxiliar do judiciário na prevenção de novas demandas, e ainda a própria resolução do conflito já posto em juízo. Nesse mesmo sentido, a Lei ํ‥ 9099/90 que dispõe sobre os Juizados especiais Cíveis e Criminais, foi alterada pela Lei no. 13.994/2020, para admitir a realização de audiências de conciliação não presencial, mediante o emprego de recursos tecnológicos.

O professor Dierle Nunes afirma ainda que as ODR's (Online Dispute Resolition): 
[...] podem envolver processos de negociações automatizados, gerenciados por computador, ou pode fornecer especialistas de classe mundial para administrar procedimentos de arbitragem vinculativos", chegando a solucionar sessenta milhões de conflitos por ano (BAHIA; NUNES e PEDRON, 2020, p. 457)

Já Isadora Wernek nesse mesmo sentido afirma:

[...] os novos dilemas que envolve o sistema de Online Dispute Resolition (ODR), ou Resolução de Disputas OnLine, concede o uso da tecnologia, e via de consequência, do ambiente virtual, como vetor na resolução de controvérsias - utilizando-se, muitas vezes, dos já populares métodos adequados de resolução (ADR - Appropriate Dispute Resolition), como a negociação, mediação, conciliação e arbitragem (WERNEK, 2020, p. 106).

Ademais, a autora traz ainda a origem e o conceito das Online Dispute Resolition (ODR), importante para o ponto de partida da pesquisa:

[...] De início registra-se que a definição do termo Online Dispute Resolition, dada a sua abrangência, não é uma no campo doutrinário. De acordo com Brian A. Pappas, por exemplo, ODR envolve a simples utilização das técnicas provenientes dos já consolidados métodos adequados de solução de conflitos, em um ambiente virtual. Já Colin Rule compreende que qualquer uso de tecnologia para complementar, apoiar e administrar um processo de resolução de disputas pode ser caracterizado como ODR. De forma mais abrangente, Daniel Arbix, que se apoia no conceito trazido por Ethan Kastsh, indica que ODR implica a solução de litígios online em que tecnologias de informação e comunicação não apenas substituem os "canais de comunicação tradicionais, mas agem como vetores parra oferecer às partes ambientes e procedimentos ausentes em mecanismos convencionais de dirimir conflito [...]. [...] Independentemente do conceito adotado, que vale dizer, se altera conforme a revolução do próprio sistema de ODR, certo é que este, historicamente, pode ser dividido em três estágios. O primeiro deles, que ocorreu no início dos anos 1990 e durou até a sua primeira metade, restringiu-se a situações específicas, mormente ligadas ao ambiente acadêmico (universidades e centros de pesquisa). O segundo, que vigorou de 1995 a 1998, sucedeu de forma concomitantemente ao crescimento da internet e serviu particularmente como meio de propagação dos projetos desenvolvidos no primeiro estágio, nesta feita vinculados às iniciativas públicas e privada, mas ainda majoritariamente por acadêmicos e organizações não governamentais. Já o terceiro estágio, que se iniciou a partir do final dos anos 1990, guardou estreita relação com a utilização da internet como espaço de comércio [...]. (WERNEK, 2020, p. 108/109) 
Já no contexto da pandemia os professores Daniel Becker e Erik Navarro Wolkart (2020), afirmam que esta é a oportunidade para a aceleração do processo de digitalização do Judiciário brasileiro", ressaltando:

[...] Neste artigo, defendemos que a pandemia do Covid-19 cria uma oportunidade para a aceleração do processo de digitalização da Justiça brasileira. Para que esse movimento seja bem-sucedido, é preciso que se observem os métodos tecnológicos de abordagem de conflitos utilizados pelas mais diversas plataformas de online dispute resolution (ODR). Como veremos, não parece ser esse o caminho atualmente trilhado pela Justiça Brasileira.

A pandemia do Covid-19 alterou a dinâmica de trabalho nas últimas semanas. Para determinados setores da economia, já digitalizados, a transição foi branda, enquanto, para outros, houve uma desastrosa desestabilização. No Poder Judiciário, a prorrogação e a suspensão de prazos, decorrentes da ordem de fechamento das portas dos tribunais, deram-se acertadamente à luz das recomendações da Organização Mundial da Saúde (OMS), e das mais variadas instâncias governamentais - não todas, diga-se [...] (BECKER, 2020).

Para finalizar, Tainá Aguiar Junquilho conclui que:

[...] O Brasil vive um contexto da promoção e compreensão da Justiça Multiportas, que compreende que o acesso à resposta justa pode ser buscado da forma mais adequada por meio de diversas maneiras que não somente a jurisdição clássica. Concomitantemente, a sociedade tem se utilizado cada vez mais da internet e da comunicação por meio virtual o que traz como uma das consequências dessas mudanças a criação de novas ferramentas que visam aliar a ideia de autocomposição às novas tecnologias [...]. (JUNQUILHO, 2020, p. 195)

As plataformas virtuais vieram para trazer uma solução mais célere, prática e econômica para o judiciário e jurisdicionado brasileiro, mas ainda há muito que evoluir. O uso da tecnologia deve servir para incluir e não criar um entrave de acesso a justiça pelo jurisdicionado.

\section{AS PLATAFORMAS DE ODR}

Como informado alhures, as plataformas de ODR (online dispute resolutions) vem ganhando espaço no Brasil aliando o conceito de justiça multiportas com a virada tecnológica do Direito, assim denominada por Dierle Nunes (2020). 
É sabido que o Brasil é conhecido por sua litigiosidade em massa, todavia, os meios alternativos de resolução de conflitos se tornam mais atrativos e vantajosos por serem autocompositivos, ou seja, as próprias partes constroem a solução para o seu litígio, analisando as vantagens, custos e os riscos de judicializar aquela demanda. Assim, o acesso à justiça não deve ser compreendido apenas como acesso à jurisdição estatal, mas ainda por qualquer outra via adequada de composição (DIDIER JUNIOR; ZANETI, 2017, p. 112)

Assim surgem as plataformas de ODR, como meio alternativo e adequado de resolução de conflito, que busca ainda atender às necessidades de um mercado cada vez mais célere e conectado à rede mundial de computadores, com maior eficácia e economia de tempo e dinheiro.

A resolução de disputas online é quando se "utiliza da tecnologia para "complementar, apoiar ou administrar o processo de solução de um litígio" (RULE, 2002, p. 44). Desse modo, a tecnologia é o instrumento de aproximação das partes, seja através dos meios tradicionais de autocomposição, seja por novos métodos, mas sempre com recurso tecnológico.

Tainá Aguiar Junquilho (2020, p. 189) em seu texto afirma que a doutrina no geral, classifica basicamente quatro formas de ODR, que estão descritas no quadro abaixo: 
Quadro 1: formas de ODR

\begin{tabular}{|c|c|}
\hline $\begin{array}{l}\text { E-negociacão/ } \\
\text { Negociação on- } \\
\text { line }\end{array}$ & $\begin{array}{l}\text { E-negociacão automatizada: totalmente automatizada. Partes do } \\
\text { conflito submetem/enviam uma ou mais proposta(s) e } \\
\text { contraproposta(s) monetárias on-line, que são mantidas ocultas } \\
\text { durante a negociação. O algoritmo combina as ofertas, calcula a } \\
\text { média aritmética das propostas realizadas e, por ai atinge-se o } \\
\text { consenso. }\end{array}$ \\
\hline & $\begin{array}{l}\text { E-negociacão assistida: as partes chegam ao consenso se } \\
\text { comunicando pela internet (por e-mail, videoconferência etcc) }\end{array}$ \\
\hline $\begin{array}{l}\text { E-mediacão/ } \\
\text { Mediação on-line }\end{array}$ & $\begin{array}{l}\text { Forma tradicional da mediação (presença de um terceiro neutro que } \\
\text { ajuda as partes no diálogo), que ocorre on-line e não off-line, como na } \\
\text { comum. }\end{array}$ \\
\hline $\begin{array}{l}\text { E-arbitragem/ } \\
\text { Arbitragem on- } \\
\quad \text { line }\end{array}$ & $\begin{array}{l}\text { Também se assemelha à forma tradicional de arbitragem (presença } \\
\text { de um terceiro escolhido pelas partes ou por terceiro que decide após } \\
\text { ouvir os argumentos levantados), mas se desenvolve on-line. }\end{array}$ \\
\hline
\end{tabular}

Fonte: elaborada pela autora a partir de Goodman (2003) e Porto; Nogueira e Quirino (2017).

As plataformas de ODR, sejam elas de qualquer forma descrita acima, já é tendência mundialmente. Um dos percussores no ramo é o E-Bay, um site de e-commerce que conecta diariamente milhões de usuários em compra e venda de produtos e serviços, o que gera, em razão do grande volume de transações comerciais, também reclamações e eventuais demandas jurídicas.

Pensando dessa maneira, o site criou uma alternativa própria de resolução de suas demandas, já solucionando hoje mais de 60 milhões de casos por ano. Se o E-Bay fosse um Tribunal, estima-se que ele seria o maior Tribunal do mundo em resolução de demandas, alcançando ainda uma média de $90 \%$ de desjudicialização.

O sistema utilizado pelo E-Bay possui uma fase de negociação entre as próprias partes, onde estas dialogam dentro do próprio site, sobre a controvérsia da demanda. Caso as partes não entrem em consenso, estes poderão oferecer manifestações escritas, anexando documentos, e um terceiro, colaborador do E-Bay irá definir no 
caso concreto a que parte assise razão, estabelecendo os limites e as regras internas do site.

Atualmente o E-Bay constituiu seu próprio sistema in-house de resolução online de conflitos, o E-Bay Resolution Center, que é coordenado por Colin Rule, um dos maiores especialistas em ODR mundialmente.

A partir do E-Bay várias plataformas semelhantes começaram a surgir. No Brasil foi lançado o portal consumidor.gov.br[5], pela Secretaria Nacional do Consumidor, vinculado ao Ministério da Justiça, conta até a data final desse artigo com mais 3.402878 (três milhões, quatrocentos e dois mil e oitocentos e setenta e oito) reclamações finalizadas, 2.460392 (dois milhões, quatrocentos e sessenta mil e trezentos e noventa e dois) usuários e 932 (novecentos e trinta e dois) empresas cadastradas.

A plataforma é bastante intuitiva e permite o contato direto entre consumidor e fornecedor do produto ou serviço, para a composição do litígio, através da rede mundial de computadores, vejamos:

[...] Monitorada pela Secretaria Nacional do Consumidor - Senacon do Ministério da Justiça, Procons, Defensorias, Ministérios Públicos e também por toda a sociedade, esta ferramenta possibilita a resolução de conflitos de consumo de forma rápida e desburocratizada: atualmente, $\quad 80 \%$ das reclamações registradas no Consumidor.gov.br são solucionadas pelas empresas, que respondem as demandas dos consumidores em um prazo médio de 7 dias.

O Consumidor.gov.br coloca as relações entre consumidores, fornecedores e o Estado em um novo patamar, a partir das seguintes premissas:

Transparência e controle social são imprescindíveis à efetividade dos direitos dos consumidores;

As informações apresentadas pelos cidadãos consumidores são estratégicas para gestão e execução de políticas públicas de defesa do consumidor; 
O acesso a informação potencializa o poder de escolha dos consumidores e contribui para o aprimoramento das relações de consumo.

Por se tratar de um serviço provido e mantido pelo Estado, com ênfase na interatividade entre consumidores e fornecedores para redução de conflitos de consumo, a participação de empresas no Consumidor.gov.br, só é permitida àqueles que aderem formalmente ao serviço, mediante assinatura de termo no qual se comprometem em conhecer, analisar e investir todos os esforços disponíveis para a solução dos problemas apresentados. O consumidor, por sua vez, deve se identificar adequadamente e comprometer-se a apresentar todos os dados e informações relativas à reclamação relatada [...]. (Disponível em <https://consumidor.gov.br/pages/principal/?1605630433404> acesso em 10 de novembro de 2020).

Assim como o consumidor.gov, outras plataformas começaram a surgir no mercado brasileiro com a finalidade de resolver de forma célere, econômica e eficaz os litígios que são postos perante as partes, não apenas de natureza consumerista, mas de qualquer ordem jurídica.

Desse modo, diversas lawtechs ou legaltechs surgiram no Brasil com esse propósito, tendo a sua importância reforçada ainda mais com a pandemia da COVID-19. No site da Associação Brasileira de lawtechs ou legaltechs (AB2L)[6] consta o registro de pelo menos 19 empresas de ODR ativas no Brasil e esses números tendem a aumentar devido à adesão das partes pela facilidade do meio empregado e pela forma consensual e simples como estas solucionam os seus próprios litígios, sem a imposição de um terceiro alheio ao problema, através de um sistema jurídico por muitas vezes caro, burocrático e desgastante psicologicamente.

Todas essas vantagens têm tornado as ODR's uma tendência mundial de descongestionamento dos judiciários e pacificação social, que é a grande finalidade do Direito, o que às vezes mesmo com uma sentença judicial, na prática, não é alcançada pelo judiciário, pois o magistrado pode ter posto fim ao processo, mas não ao litígio em si, as partes continuam equidistantes e insatisfeitas com a solução dada para o caso concreto.

\section{CONSIDERAÇOES FINAIS}


Ao final, se conclui que os benefícios do emprego ou utilização das ODR's (Online Dispute Resolition), como um sistema multiportas de resolução de demandas, é para além da prevenção de eventuais litígios, mas sobretudo, na resolução de forma efetiva, célere e simplória do conflito, aproximando as partes e estabelecendo o status quo da relação estabelecida entre as partes.

As ODR's (Online Dispute Resolition) é uma aposta da tecnologia para a seara jurídica, como método alternativo de solução de conflitos diverso dos tradicionais, com maior simplicidade, eficácia e economia.

Os meios consensuais de solução de litígio são mais econômicos do que um processo judicial, muitas vezes mais efetivo tendo em vista que as próprias partes decidem o resultado do seu conflito, sem a imposição de um terceiro julgador.

Assim, as ODR's (Online Dispute Resolition) é um ambiente virtual onde são celebrados acordos extrajudiciais, utilizando-se de não apenas um meio de resolução de conflito, mas aquele que melhor atender à necessidade das partes naquele caso concreto.

\section{REFERÊNCIAS}

ALVES, Isabella Fonseca. Inteligência Artificial e Processo. Belo Horizonte: Editora D'Plácido, 2020.

BAHIA, Alexandre, NUNES, Dierle, PEDRON, Flávio Quinaud. Teoria Geral do Processo: com comentários sobre a virada tecnológica no direito processual. Salvador: Editora JusPodivm 2020.

BECKER, Daniel. WOLKART, Erik Navarro. Isaac Newton, e Bay e canelas de gigantes: Covid-19 e o futuro da Justiça - Pandemia traz oportunidade para a aceleração do processo de digitalização do Judiciário brasileiro. Disponível em $<$ https://www.jota.info/coberturas-especiais/inova-e-acao/isaac-newton-ebay-ecanelas-de-gigantes-covid-19-e-o-futuro-da-justica-14042020> Publicado em 14/04/2020. Acesso em 06.06.2020. 
CONSUMIDOR.GOV.BR.2020.

<https://consumidor.gov.br/pages/principal/?1605630433404>. Acesso em 10 de nov. 2020.

DIDIER JR, Fredie. ZANETI JR, Hermes Zaneti. Justiça Multiportas e Tutela Constitucional Adequada: Autocomposição em Direitos Coletivos. 2017. Disponível

em<file:///C:/Users/Debora/Downloads/Justica_multiportas_e_tutela_constitucio.pdf> Acesso em 06.06.2020>.

Justiça em Números 2020/Conselho Nacional de Justiça - Brasília: CNJ, 2020. Disponível em <https://www.cnj.jus.br/wp-content/uploads/2020/08/WEB-V3Justi\%C3\%A7a-em-N\%C3\%BAmeros-2020-atualizado-em-25-08-2020.pdf>. Acessado em 10 fev. 2020.

NUNES, Dierle, LUCON, Paulo Henrique dos Santos, WOLKART, Erik Navarro. Inteligência Artificial e Direito Processual - Os impactos da virada tecnológica no direito processual. Salvador: Editora JusPodivm, 2020.

SAMARCO, José Benedito [et al.]. Indústria 4.0: conceitos e fundamentos. São Paulo: Editora Blucher, 2019.

SCHWAB, Klaus. A Quarta Revolução Industrial. Editora Edipro, 2016.

\section{APÊNDICE - REFERÊNCIA DE NOTA DE RODAPÉ}

4. Disponível em <https://www.cnj.jus.br/wp-content/uploads/2020/08/WEB-V3Justi\%C3\%A7a-em-N\%C3\%BAmeros-2020-atualizado-em-25-08-2020.pdf> Acessado em 10 de novembro de 2020.

5. Disponível em <https://consumidor.gov.br/pages/principal/?1605630433404> acesso em 10 de novembro de 2020.

6. Disponível em <https://ab2l.org.br/> acesso em 10 de novembro de 2020. 
Enviado: Novembro, 2020.

Aprovado: Junho, 2021. 